ARTICLE

\title{
Using currency demand to estimate the Palestine underground economy: An econometric analysis
}

Ibrahim M. Awad ${ }^{1 凶} \&$ Wael Alazzeh ${ }^{1}$

\begin{abstract}
The existence of an underground economy may hide the official number of unemployed persons, their share in the labour force, and wages. It also gives rise to the economic and social conditions of individuals, household and countries, which are evaluated in a biased way if one relies on the official statistics. In this paper, we use the currency demand model of Tanzi to estimate the underground economy in Palestine over the period: (2008-2017). Toward that end, a group of econometric techniques of time series data was applied. The main empirical results show that the underground economy reached up to $28.6 \%$ in 2010 of the GDP with about USD 2676.227 million. The empirical study results also reveal that the explanatory variables listed in the study model suggested by economic theory and previous research have a significant impact on the dependent one, except the variable ratio of governmental wages and salaries to GDP. However, the money received by the government employees does not contribute to the underground economy.
\end{abstract}

\footnotetext{
${ }^{1}$ Faculty of Business and Economics, Al-Quds University, Jerusalem, Palestine. ${ }^{凶}$ email: iawad@staff.alquds.edu
} 


\section{Rationale}

he underground economy is considered as an important source for job opportunities and diverse labour of children, women, youth, elderly, disabled increasing burdens of decision-makers who should necessarily take this kind of economy and its connections including health, provision of decent work social insurance and other benefits into consideration in planning. All of this sheds light on the nature of works and underground labourers and work environment that is placed outside legal and real structures and organizations. The Anthropologist Keith Hart, who discovered the underground economy as a new concept in the area of humanities, so that he presented a working paper during a conference of unemployment in rural areas of Africa in 1971, where he discussed the issue of the poor in urban areas. Hart stressed the fact that those poor are not unemployed, since they usually received meagre and irregular wages, are not included in administrative organizations. The problem is being complicated by the fact that this kind of economy has diverse forms, but it works according to one principle, that is the principle of confidentiality of lack of publicity). It has different goals but having economic determinism tendency, which means refusal to connect and refer all phenomena to their economic aspect.

Medina and Schneider (2018) showed that the size of informal during the years (1991-2015) $17.38 \%$ and consequently, the informal economy in Jordan was at its minimum of $13.44 \%$ and its maximum $21.12 \%$. On the level of Arab countries, the working paper that includes 158 of world countries showed that the average rate of informal economy in Qatar reached $15.93 \%$ of GDP since 1991 till 2015, 16.56\% in Saudi Arabia, 16.56\%, $19.58 \%$ in Syria, while its rate increased in Egypt 34.24\%, Morocco $34.1 \%$, Lebanon $31.58 \%$, Algeria $30.86 \%$, and the United Arab Emirates $26.45 \%$. On the International Level, the average rate reached $31.9 \%$, and Switzerland has been the least countries in the rate of the informal economy of GDP, which reached $2.7 \%$, followed by Austria with $8.09 \%$. Bolivia has the highest rate with $62.3 \%$ and Zimbabwe, with a rate of $60.6 \%$.

Similar to the conditions of the world countries namely the developing countries, the Palestinian economy has suffered from the consequences of any other underground economy, further to the Israeli occupation, and political and geographical division between West Bank and Gaza Strip, fragile governmental organizations and lack of full control over the geographic areas. The West Bank had been divided into areas (A, B and C) according to Oslo accords weakening the full control and sovereignty over the West Bank and Gaza Strip. Accordingly, It is difficult for the Palestinian government to perform its functions in controlling its economy due to this unique political situation.

The informal economy should be considered along with the formal economy to design a Palestinian economic development plan because excluding the informal economy and its activities and variables in that plan will not achieve the goals of that plan or estimate the entire size of the Palestinian economy. Many tools used in estimating the size of the underground economy. Each tool has its specifications and defects that will be explained later in this study. Means of the underground economy and its impacts will be demonstrated. All the aspects of the concept of economic development will be clarified. so that the impacts of the size of the underground economy and to what extent they affect the Palestinian economy in general and economic development.

On the other hand, it is noted that the most used model is Tanzi-Model (Tanzi, 1983), which is based on the cash to money supply ratio. However, this study will apply this model to estimate the underground economy in Palestine. This method is the most used in estimating the size of the hidden economy and the most critical as well. It depends on its evaluation on the hidden economy transactions that use cash (liquidity) to easily hide the dealers in the hidden economy of their transactions from using other payment methods, such as electronic payments, this method assumes transactions in a hidden economy would take place on in the form of cash payments, and the increase in the size of the hidden economy will then lead to a rise in the demand for money. To assess the excessive demand for money, economists use the standard money demand equation to evaluate it over time (Medina and Schneider, 2018). This excessive increase in money represents the amount, which was explained using the econometric equation or determining the amount of money in circulation that moves us from the formal economy to the hidden economy, by estimating the difference between the demand for money in the economy as a whole and the demand for money needed to finance transactions in the formal economy, which represents the financing of economy transactions to be hidden, through which the speed of money circulation can be measured in the hidden economy, compared to the speed of money circulation in the formal economy in the absence of the hidden economy during the period that separates them, due to the high tax burden and other factors that motivate individuals to work in the hidden economy. In contrast, this method is not without the following weaknesses: (1) not all transactions in the underground economy are paid in cash, and most studies consider only one specific factor, the tax burden, as the cause of the underground economy; (2) assuming that money circulates at the same speed in both economies; (3) supposing that there is no hidden economy in the base year, a problem in itself; and (4) taking advantage of this method requires the calculation of liquid money to be among the equation by which the size of the hidden economy was calculated.

\section{Underground economy}

One commonly used working definition is all currently unregistered economic activities that would contribute to the officially calculated (or observed) gross national product if observed (Feige, 1989, 1994; Schneider, 1994a, 2005, 2011; Frey and Pommerehne, 1984). Smith (1994) uses the definition "market-based production of goods and services, whether legal or illegal, that escapes detection in the official estimates of GDP." One of the broadest definitions includes "those economic activities and the income derived from them that circumvent government regulation, taxation or observation" (Dell'Anno, 2003; Del'Anno and Schneider, 2004; Feige, 1989). As these definitions still leave a lot of questions unanswered, Table 1 offers a reasonable consensus for a description of the underground (or underground) economy. As shown in Table 1, it is clear that a broad definition of the underground economy includes unreported income from the production of legal goods and services either from monetary or barter transactions, including all economic activities that would generally be taxable were they reported to the tax authorities (Schneider and Buehn, 2018). Accordingly, there are numerous nomenclature and absolute terms on this economy, and the terminology of the term is broken down into three groups as shown in Table 1.

The first group refers to the concept of secrecy: Several terms have been coined to denote the confidentiality of the phenomenon, the most prominent of which are: underground economy, black economy, secret economy, hidden economy, The previous titles give the impression that the apparent activities are considered illegal, as they indicate confidentiality to them, but it is not possible to say that all the vocabulary of the phenomenon illegal due to the presence of some legitimate activities. However, they are not declared and do not fall within the national accounts. For example, concerning illegal activities, they are trafficking in stolen goods, drug trafficking and smuggling. As for legitimate 
Table 1 A taxonomy of types of underground economic activities (Lippert and Walker, 1997).

\begin{tabular}{|c|c|c|c|c|}
\hline $\begin{array}{l}\text { Type of } \\
\text { activity }\end{array}$ & \multicolumn{2}{|l|}{ Monetary transactions } & \multicolumn{2}{|c|}{ Non-monetary transactions } \\
\hline $\begin{array}{l}\text { Illegal } \\
\text { activities }\end{array}$ & \multicolumn{2}{|c|}{$\begin{array}{l}\text { Trade with stolen goods, drug dealing and manufacturing, prostitution, } \\
\text { gambling, smuggling, fraud, etc. }\end{array}$} & \multicolumn{2}{|c|}{$\begin{array}{l}\text { Barter of drugs, stolen goods, smuggling, etc. } \\
\text { Producing or growing drugs for own use. Theft for } \\
\text { own use }\end{array}$} \\
\hline & Tax evasion & Tax avoidance & Tax evasion & Tax avoidance \\
\hline $\begin{array}{l}\text { Legal } \\
\text { activities }\end{array}$ & $\begin{array}{l}\text { Unreported income from self-employment; Wages, } \\
\text { salaries and assets for unreported work related to legal } \\
\text { services and goods. }\end{array}$ & $\begin{array}{l}\text { Employee discounts } \\
\text { fringe benefits. }\end{array}$ & $\begin{array}{l}\text { Barter of legal } \\
\text { services and goods }\end{array}$ & $\begin{array}{l}\text { All do-it-yourself work and } \\
\text { neighbour help }\end{array}$ \\
\hline
\end{tabular}

and undeclared activities of government authorities, they are the unreported business income, wages, salaries, and assets that an individual obtains from unreported businesses, the discounts, and additional benefits granted to employees.

The second group refers to the concept of irregularity; this group suggests the irregularity of the phenomenon and the most prominent terms that were used to name the phenomenon according to the idea of the informal economy. Many theorists considered this concept as a narrow one because irregularity is not restricted to illicit regimes, but rather it concerns the challenging industries sector, street vendors, handicrafts and craftsmanship which are illegal and not subject to the laws of the state.

The third group refers to the relationship with the formal economy: that phenomenon as a dynamic process that affects and is affected by the formal economy, and many prefer to use one of the concepts of this group as that most of the phenomenon is the result of a reaction to the policies announced in the formal economy. However, the definition of the informal economy differs according to the views of different economists and international economic organizations.

Given that, the informal economy can be defined as an economy that includes income generated by legitimate means, but the revenue generated from it is not announced with the tax authorities, as well as income from non-illegal activities. It also includes all transactions and in-kind exchanges that take place without the use of money and in a general sense, the total income that does not enter Within the national accounts.

Causes of the underground economy. There are numerous reasons attributed to the cause of an underground economic situation in various countries. The increase of tax burden and social security contributions were observed in the literature as one of the most important reasons influencing the size of the underground economic activities. Gutmann (1977) found that high taxes and government regulation are the leading causes of the existence of an underground economy. As is known, taxes affect labour-leisure choices of economic agents and also encourage labour supply towards the underground or untaxed sector of the economy (Ogunc and Yilmaz, 2000). Higher tax and social security contributions can lead to lower taxable income for employers, and so it can create an incentive for employers to work in the underground economy by employing workers from the underground economy, to reduce their cost of production. Schneider $(2005,2008)$ indicated that the more significant the difference between the total cost of labour in the official economy and the after-tax earnings (formwork), the higher the incentive to avoid this difference and to work in the underground economy. Perception of fairness and justice, in the tax system, does affect the incidence, as well as the size of the underground economies. All working adults of a population are expected to pay their due of taxes. When people perceive their neighbours as not paying their full due of taxes, it serves as an incentive for them not to pay too. Tyler et al. (1997) revealed that even if paying tax means less money in a person's pocket; there is a perception of fairness knowing that everyone else who earns an income is also paying their share of taxes. Previously, it shows the critical role that tax incentives play influencing the size of the underground economy.

The role of the institution in influencing the size of the underground economy cannot be overemphasized. Indicated that the probability of detection and the size of the fine imposed determines the amount of income evaded (Becker, 1968). Based on weak institutions, a purely economic analysis of the evasion gamble implies that most individuals would evade if they are "rational," because it is unlikely that cheaters will be caught and penalized by the institutions. (McClelland and Schulze, 1992). However, consistent enforcement of appropriate system is necessary to be taken into consideration (Dybka et al., 2019).

\section{Methodology}

Origins of the currency demand analysis. Currency demand analysis of the underground economy is based on the assumption that most of the unregistered transactions are settled with cash. In an early contribution, Cagan (1958) noticed that changes in the ratio of cash to a broader monetary aggregate might reflect the evolution of SE. He discussed potential determinants of this ratio and identified the level of taxation as a possible driver of the nonobserved economy in a straightforward currency demand equation, however without any derivation of the underground economy level. In a similar vein, Gutmann (1977) developed a simplified 'fixed ratio approach', in which he assumed that there was no underground economy in some given, past period and that a 'natural' ratio of cash to deposits from that period should remain stationary over time. Instead, he observed a growth of the ratio and deduced that this increasing 'surplus' of cash in circulation was related to the underground economy. Using an estimate of the money velocity, he translated this surplus into the size of the underground economy (in \% of GNP). As a response to this work (Feige, 1986) proposed his 'transaction method' that was derived from the equation of exchange. This method requires the knowledge of the value-added and the stock of money in the economy, as well as the level of the underground economy itself in some baseline period. One must also assume that the ratio of the value of all transactions to the value-added in the economy is stationary over time. A summary and critique of the described monetary methods can be found in a handbook on measuring the non-observed economy. It is also worth noting that, without an assumption on the underground economy level in a certain period, the methods of Gutmann and Feige allow only for the analysis of the dynamics of the underground economy. Tanzi (1980, 1983) developed the analysis of links between cash usage and the underground economy. Cagan (1958) estimated an equation where the ratio of cash to M2 monetary aggregate was explained with various control variables, including the level of taxation. In one variant of his analysis, he noticed that the cash 
level attributable to the underground economy might be calculated as a difference between the total cash demand and cash demand estimated from a model in which the tax variable was set equal to zero. While such an approach is based on an extreme out-of-sample prediction, it allows translating the underground economy cash into the share of the underground economy in total GNP (including underground economy) based on the assumption of the equal velocity of money in the underground and observed economy. To calculate the monetary value of the underground economy, Tanzi also hinges upon the assumption that the official GNP estimate does not include any underground economy activities (Tanzi, 1980, 1983). The premise of equal velocity freed Tanzi from a more controversial assumption on the level of the underground economy in a given period. It is worth noting that Tanzi's approach enables the estimation of the level of the underground economy using the currency demand analysis, since Tanzi's contribution, various versions of the CDA have been used for the estimation of the underground economy in different countries (Asiedu and Stengos, 2014).

Analysis of the currency demand. According to the measuring procedures and means used by the researchers, they use to adopt an econometric analysis of time series data in this empirical study with considering the cutting issues that can play a crucial role for avoiding any possibility of overestimation in the study results. Notably, the estimation of the underground economy in Palestine and what factors may or may not affect this important economic indicator are of exceptional and significant value to both policymakers and researchers.

This study relies on the model suggested by Tanzi. The Tanzi's model is based on the fact that all treatments of underground economy are achieved with the use of cash (Tanzi, 1999). To this end, these assumptions are taken into account: (1) all transactions of the underground economy are made with the use of cash for tax evasion and the increase in the underground economy will cause an increase in the demand to the cash; (2) activities of the underground economy are a direct result of high taxes. Thus, any change affecting the tax rate in the model will affect the cash value connected with the underground economy, that is, the size of the underground economy underestimation; (3) the rotation speed of money in the underground economy and the formal economy are equal; and (4) using the cash to money supply ratio with its broad meaning M2, but not with its narrow meaning of M1.

Based on the preceding, we adopted the following model:

$$
\begin{aligned}
\ln (\mathrm{CC} / \mathrm{M} 2)_{t}= & \beta 0+\beta 1 \ln (1+(T / Y))_{t}+\beta 2 \ln (W / Y)_{t} \\
& +\beta 3 R_{t}+\beta 4 \ln (\mathrm{SE})_{t}+\beta 5 \ln (\mathrm{GDPpc})_{t}+\varepsilon_{t} \ldots
\end{aligned}
$$

where (CC/M2): the rate of cash outside the back system to the ratio of supply of money; $(T / Y)$ : the ration of tax (without clearing) to the ratio of GDP; $(W / Y)$ : the ratio of wages and government salaries to the ratio of GDP; $(R)$ : the price of revenue on saving deposits in US dollar in commercial banks; (SE): rate of workers in their private business to the real ration of workers in Palestine; (GDPpc): GDP per capita; and $(\varepsilon)$ : error term.

However, the variable of $(T / Y)+1$ is used in this form due to the use the natural logarithm in the model where the mechanism of a model for estimating the size of the underground economy, with considering the assumption that the tax $(T)$ does not equal zero for one time, while it equals zero, and (1) was added to the variable for the math calculation. It was assumed that $T=0$ and $0=T / Y$ and because $\operatorname{Ln}(0)=-\infty$, the researchers added (1) in order to get the value of $\{\operatorname{Ln}(1+0)=\operatorname{Ln}(1)=0\}$, and therefore the variable tax would fully be identified one, the required quantity of cash is estimated.

Estimation of the underground economy. According to the mean of the demand to cash that was used by Tanzi which assumes that the main engine for the underground economy is tax evasion, the work of model will have proceeded through the following four phases:

1. The condition of cash is estimated outside the ban system (CC), the first estimation: ( $\mathrm{Tax} \neq 0) \mathrm{CC} 1$ tax variable does not equal zero, the second estimation: $(\operatorname{Tax} \neq 0)$ CC2 tax variable equals zero.

2. Finding the difference between the two estimations (CC2 $-\mathrm{CC} 1$ ) and that difference is considered as illegal cash and the point here is the difference between cash outside bank system within the existence of taxes and cash outside the bank system within the existing taxes.

3. Depending on Tanzi model which assumes that the formal economy equals the underground economy, we can calculate the underground economy through multiplying illegal cash by the speed rotation which can be calculated through GDP divided by cash supply within its broad meaning (the speed rotation of $\mathrm{cash}=\mathrm{GDP} / \mathrm{M} 2$ ).

4. The rate of the underground economy is estimated with revenue of the size of the underground economy divided by GDP (the ratio of the underground economy = the value of underground economy/the value of GDP).

\section{Econometric techniques}

Unit root tests. The stationarity of time series data is one of the critical issues in many applications that depend on time data such as economic and financial data. It is also a vital issue having applied, and vital nature in the metric analysis since the interference of nonstationary variables could produce misleading results because the relationship between variables is not real while it could be misleading (Kwiatkowski et al., 1992). Many statistical tools are used to test the stationarity of data. If the time series data is stationary after taking the first difference, the original series will be integral from the first grade (integrated of order), which is (1), but if the series is stationary after getting the second difference, (first discrepancies for the first discrepancies), the first series will be integrated in the second grade, which (2) I and thus if the original series is stationary in its original value, it will be integrated in the grade of zero, and it does not carry the root of the unit, which (0) I. In general, the series $x t$ will be integrated from the degree of $(d)$ if it becomes stationary after taking the difference $(d)$. For testing the stationary of time series data and identifying their degree of integration, the study uses the tests the Augmented Dickey-Fuller test (ADF).

Augmented Dickey-Fuller test. The ADF test allows for higherorder autoregressive processes by including $(\Delta y t-p)$ in the model, but the test is still as is if $g=0$.

$$
\Delta y t=\alpha+\beta t+g y t-1+\delta 1 \Delta y t-1+\delta 2 \Delta y t-2^{+\cdots}
$$

where $p$ : the degree of the model; $\varepsilon$ : random error; $\Delta y t$ points to the first difference of the time series $Y t$.

Accepting the null hypothesis for both tests is that the data are non-stationary so that we need to reject it for having stationary data. Fuller test-ADF is one of the most tests used in testing the stationary of time series and identifying the degree of integration (Said and DIickey, 1984). 
Engle-Granger test for cointegration. Engle-Granger test for cointegration starts with estimating the regression of the longterm relationship of the standard model and the equation is named with cointegration regression, and then the estimation of residuals as of regression are concluded. They are a linear mixture of the regression of the long-term relationship. The focus of this test is verifying that those residuals are stationary at the level, which means that they are integrated of order (0) (MacKinnon, 1996).

Johanson cointegration test (Carolina and Pau). The cointegration test suits to the small samples and it is used in the case of the existence of two or more variables and the most critical point are that the test can find whether there is cointegration, which means cointegration can be achieved only in the case of the regression of dependent variables over independent variables. This has its significance in the theory of cointegration pointing to the fact that if there is no unique cointegration, the balanced relationship between variables is questioned.

The existence of long-term balance between the two stationary time series variables of the same order is tested despite the existence of short-term disruption by through cointegration test of variables with the use of Johanson cointegration test which is used in the models that consist of more than two variables which is considered the best test even in the case of the existence of two variables only as they are distinguished with mutual impact between the variables of the study. This kind of tests consists of two types, one is called Trace, and the other is maximum eigenvalue (Hanninen, 2012).

Vector error correction model (VECM). An error correction model belongs to a category of multiple time series models most commonly used for data where the underlying variables have a longrun stochastic trend, also known as cointegration. It adjusts to both short-run changes in variables and deviations from equilibrium. Lag length criteria also suggest the chosen of one lag for estimating VECM. The general formula of the VECM model used is

$$
\Delta Y t=a_{1}+a_{2} \mathrm{EC} t-1+a_{3} \Delta Y t-1+a_{4} \Delta X t-1+\in t
$$

A crucial parameter in the estimation of the VECM dynamic model is the coefficient of the error correction term, (EC $t-1)$, which measures the speed of adjustment of economic growth to its equilibrium level (Engle and Granger, 1987).

Estimating the function of the study model. After verifying the existence of the long-term cointegration relationship between the variables of the study model, the function of demand to cash in Palestine will be estimated with the use of a standard tool suiting the variables of the study to estimate the function of the proposed study model. Fully modified ordinary least squares (FMOLS) was used (Montgomery et al., 2012).

Estimating the function of study model with the use of FMOLS. The function of the regression of the dependent variable with independent variables was estimated by the use of ordinary least squares (OLS), which correct errors when the criteria of the ordinary mean are not fulfilled namely the problem of the autocorrelation. If FMOLS were used in estimating the model, there would be no need to check the problems of the autocorrelation and coherence of variation for the series of residuals (Park, 1992). The full linear relationship between two or more independent variables means that those two variables actually indicate on variable and one can fully replace the other. Therefore, the explanatory rate of one variable will be the rate of the other. This will make analysis impossible with the use of OLS. Also, the specialist statistical programs cannot produce the outcomes of analysis in this case.

To check the linear problem correlation between independent variables, the matrix of the correlation coefficient between independent variables were calculated. Also, tests were used for one sample to test that arithmetic mean of residuals equals zero, and the model of time series is developed based on this assumption. Jarque-Bera test was used to make sure that data is normally distributed (Razali and Wah, 2011).

\section{Empirical results}

In the context of this critical section of the study, the primary and most important empirical results are shown and discussed. Some results of the econometric techniques shown above are critically considered in the analysis, but they are not shown separately. On the other hand, this phenomenon is one of the aspects that are difficult to measure adequately, especially since sometimes it is not possible to obtain all the necessary information according to the different circumstances depending on the countries.

Regarding the conditions arising in the Palestinian territories, according to the use of the cash-based model, it is not possible to include all the information, and it covers part of this phenomenon, but not the whole of it, for the following reasons:

1. The lack of full sovereignty over the state.

2. The lack of currency of the country and the work of currencies traded four (Israeli shekels-US Dinar-JD-Euros).

3. Inability to obtain full wages and salaries for workers, due to the presence of workers who do not work within the limits of the administrative sovereignty of the Palestinian territories.

4. Lawlessness in some lands that are not subject to sovereignty.

5. The lack of information and data with government agencies.

Estimating the size of the underground economy in Palestine. After verifying that models are statistically flawless, the estimated regression equation will be in the following form:

$$
\begin{aligned}
& \operatorname{Ln}(\mathrm{CC} / M 2)_{t}=7.9794-11.1621^{*} \operatorname{Ln}(1+T / Y)_{t} \\
& \quad+0.0804^{*} \operatorname{Ln}(W / Y)_{t}-0.515^{*} \operatorname{Ln}(R)_{\mathrm{t}}+0.924^{*} \operatorname{Ln}(\mathrm{SE})_{t} \\
& \quad-1.1532^{*} \operatorname{Ln}\left(\mathrm{GDP}_{\mathrm{PC}}\right)_{t}
\end{aligned}
$$

Based on the previous regression equation, two estimations for the variables of cash outside the bank system will be found (currency cash) (CC). The first estimation will be in the normal equation when the variable of tax stays the same. The second estimation will be when the value of the tax variable is equated with zero. The variation between the two estimations will be illegal cash, and they multiply to the speed cash rotation, assuming that they are equated in the formal and underground economy. The estimation of the underground economy is concluded. Table 2 demonstrates the estimation of the size of the underground economy in Palestine during the years of the study. Based on the estimated model with the use of FMOLS.

According to Table 2, Fig. 1 shows the change in the Palestine hidden economy over the period 2008-2017.

The VECM results. With considering the ADF test and the cointegrations tests shown in the methodology section, the error correction model shows that there is no long-term reciprocal correlation between the dependent variable and the independent variables because the error correction parameter $(0.232378)$ does 
Table 2 The size of the underground economy in Palestine from 2008 through 2017 with the use of Fully Modified Ordinary Least Squares (FMOLS).

\begin{tabular}{|c|c|c|c|c|c|c|c|c|}
\hline Year (quarter) & CC & $\begin{array}{l}\text { CC1 } \\
\operatorname{Tax} \neq 0\end{array}$ & $\begin{array}{l}\text { CC2 } \\
\operatorname{Tax}=0\end{array}$ & $\mathrm{CC} 2-\mathrm{CC} 1$ & GDP/M2 & GDP & $\begin{array}{l}\text { Underground } \\
\text { economy (HE) }\end{array}$ & $\begin{array}{l}\text { Percentage of } \\
\text { underground } \\
\text { economy }\end{array}$ \\
\hline 2008(1) & 1622.9 & 1040.49 & 1480.7 & 440.206 & 0.6248 & 2120.6 & 275.036 & 12.97 \\
\hline 2008(2) & 1622.9 & 1280.5 & 1960.5 & 679.995 & 0.6135 & 2082.4 & 417.201 & 20.03 \\
\hline 2008(3) & 1622.9 & 1386.61 & 1893.54 & 506.931 & 0.6453 & 2190.2 & 327.121 & 14.94 \\
\hline 2008(4) & 1622.9 & 1520.7 & 2074.08 & 553.379 & 0.6375 & 2163.6 & 352.756 & 16.30 \\
\hline 2008 & & & & & & & & 16.06 \\
\hline 2009(1) & 1781.9 & 1554.26 & 2236.04 & 681.784 & 0.5889 & 2149.7 & 401.532 & 18.68 \\
\hline 2009(2) & 1781.9 & 1813.02 & 2419.3 & 606.284 & 0.6362 & 2322.2 & 385.719 & 16.61 \\
\hline 2009(3) & 1781.9 & 1750.72 & 2560.74 & 810.016 & 0.6649 & 2426.8 & 538.546 & 22.19 \\
\hline 2009(4) & 1781.9 & 1828.96 & 2702.35 & 873.397 & 0.6574 & 2399.4 & 574.129 & 23.93 \\
\hline 2009 & & & & & & & & 20.35 \\
\hline 2010(1) & 1781.9 & 2008.2 & 3427.22 & 1419.02 & 0.5791 & 2377.1 & 821.819 & 34.57 \\
\hline $2010(2)$ & 1781.9 & 2067.99 & 3209.08 & 1141.1 & 0.6183 & 2537.9 & 705.564 & 27.80 \\
\hline 2010(3) & 1781.9 & 1782.29 & 2909.47 & 1127.18 & 0.628 & 2577.8 & 707.919 & 27.46 \\
\hline $2010(4)$ & 1781.9 & 1986.82 & 2994.82 & 1008 & 0.6233 & 2558.3 & 628.278 & 24.56 \\
\hline 2010 & & & & & & & & 28.60 \\
\hline $2011(1)$ & 1840.2 & 1721 & 2953.32 & 1232.32 & 0.6405 & 2719.4 & 789.299 & 29.02 \\
\hline 2011(2) & 1942.1 & 1869.48 & 2975.94 & 1106.46 & 0.6424 & 2859.2 & 710.759 & 24.86 \\
\hline 2011(3) & 1919.6 & 1905.76 & 2834.81 & 929.042 & 0.6445 & 2830.3 & 598.799 & 21.16 \\
\hline 2011(4) & 1849.9 & 1470.08 & 2343.58 & 873.497 & 0.661 & 2889.9 & 577.37 & 19.98 \\
\hline 2011 & & & & & & & & 23.76 \\
\hline 2012(1) & 1805.4 & 939.547 & 1677.94 & 738.395 & 0.9604 & 2878.4 & 709.12 & 24.64 \\
\hline 2012(2) & 1847.2 & 1449.57 & 2071.93 & 622.358 & 0.7045 & 3068.9 & 438.462 & 14.29 \\
\hline 2012(3) & 1886.97 & 1522.86 & 2276.92 & 754.056 & 0.6948 & 3053.1 & 523.892 & 17.16 \\
\hline 2012(4) & 2073.9 & 1333.52 & 2080.41 & 746.882 & 0.6426 & 3008.5 & 479.929 & 15.95 \\
\hline 2012 & & & & & & & & 18.01 \\
\hline 2013(1) & 1833.3 & 2324.49 & 4555.27 & 2230.78 & 0.3313 & 2907.3 & 739.019 & 25.42 \\
\hline 2013(2) & 1832.1 & 2044.46 & 3225.01 & 1180.55 & 0.3516 & 3132.3 & 415.118 & 13.25 \\
\hline 2013(3) & 1896.4 & 2909.33 & 4597.6 & 1688.27 & 0.3369 & 3115.7 & 568.831 & 18.26 \\
\hline 2013(4) & 1893.8 & 2164.73 & 3735.42 & 1570.69 & 0.3324 & 3119.9 & 522.025 & 16.73 \\
\hline 2013 & & & & & & & & 18.42 \\
\hline 2014(1) & 1885.5 & 1721.39 & 3975 & 2253.61 & 0.3169 & 3106.3 & 714.23 & 22.99 \\
\hline $2014(2)$ & 1871.3 & 2442.08 & 3880.27 & 1438.19 & 0.3153 & 3188.9 & 453.522 & 14.22 \\
\hline 2014(3) & 2001.5 & 3019.78 & 4665.45 & 1645.67 & 0.276 & 2879.8 & 454.184 & 15.77 \\
\hline 2014(4) & 1911.1 & 2622.36 & 3916.22 & 1293.85 & 0.3007 & 3077.9 & 389.125 & 12.64 \\
\hline 2014 & & & & & & & & 16.41 \\
\hline 2015(1) & 1891.1 & 1805.13 & 3824.39 & 2019.26 & 0.2958 & 3058.5 & 597.388 & 19.53 \\
\hline $2015(2)$ & 1987 & 2461.03 & 3908.81 & 1447.77 & 0.2959 & 3220.1 & 428.407 & 13.30 \\
\hline $2015(3)$ & 2034.8 & 2223.99 & 4181 & 1957.01 & 0.2861 & 3156.1 & 559.974 & 17.74 \\
\hline 2015(4) & 1974.4 & 2401.58 & 3718.85 & 1317.27 & 0.2907 & 3238.3 & 382.87 & 11.82 \\
\hline 2015 & & & & & & & & 15.60 \\
\hline 2016(1) & 1983.3 & 2027.64 & 4073.02 & 2045.38 & 0.284 & 3275.1 & 580.92 & 17.74 \\
\hline $2016(2)$ & 2310.3 & 2694.81 & 4167.87 & 1473.06 & 0.2802 & 3362.7 & 412.821 & 12.28 \\
\hline 2016(3) & 2221.3 & 2711.65 & 4250.8 & 1539.15 & 0.2732 & 3334.7 & 420.481 & 12.61 \\
\hline 2016(4) & 2212.1 & 2510.55 & 4053.29 & 1542.74 & 0.2684 & 3297.2 & 414.137 & 12.56 \\
\hline 2016 & & & & & & & & 13.80 \\
\hline 2017(1) & 2728.3 & 1792.97 & 3969.41 & 2176.43 & 0.2582 & 3310.8 & 561.925 & 16.97 \\
\hline $2017(2)$ & 2871.8 & 2505.25 & 4150.25 & 1645 & 0.2558 & 3396.8 & 420.808 & 12.39 \\
\hline 2017(3) & 2728.9 & 2095.09 & 3599.43 & 1504.35 & 0.2637 & 3502.3 & 396.726 & 11.33 \\
\hline $2017(4)$ & 2897.8 & 1819.09 & 3231.16 & 1412.07 & 0.2501 & 3476.5 & 353.169 & 10.16 \\
\hline 2017 & & & & & & & & 12.71 \\
\hline (2008-2017) & & & & & & & & 18.37 \\
\hline
\end{tabular}

not take the negative signal nor is it statistically significant (Prob. $=0.5070$ ), which is greater than the $5 \%$ level in Table 3 . Accordingly, the speed of adjustment of economic growth to its equilibrium level is not significant, and the variable is not likely to be adjusted in the long run.

\section{Analysis and discussion of the FMOLS results}

To examine the main hypothesis of the study, the model of underground economy regression is used with considering the size of the underground economy as a dependent variable in
Palestine, which is affected by independent variables according to the following (Carolina and Pau, 2007):

$$
\begin{aligned}
\operatorname{Ln}(\mathrm{HE})_{t}= & \beta_{0}+\beta_{1}{ }^{*} \operatorname{Ln}(T / Y)_{t}+\beta_{2}{ }^{*} \operatorname{Ln}(W / Y)_{t} \\
& +\beta_{3}{ }^{*} \operatorname{Ln}(R)_{t}+\beta_{4}{ }^{*} \operatorname{Ln}(\mathrm{SE})_{t}+\beta_{5}{ }^{*} \operatorname{Ln}\left(\mathrm{GDP}_{\mathrm{PC}}\right)_{t}+\varepsilon_{t}
\end{aligned}
$$

where $(\mathrm{HE})_{t}$ : the size of the underground economy in Palestine; $(T / Y)_{t}$ : the ratio of tax(without clearing) to Nominal GDP; $(W / Y)_{t}$ : ratio of governmental wages and salaries to Nominal GDP; $(R)_{t}$ : the price of revenue of saving deposits in US dollar in 


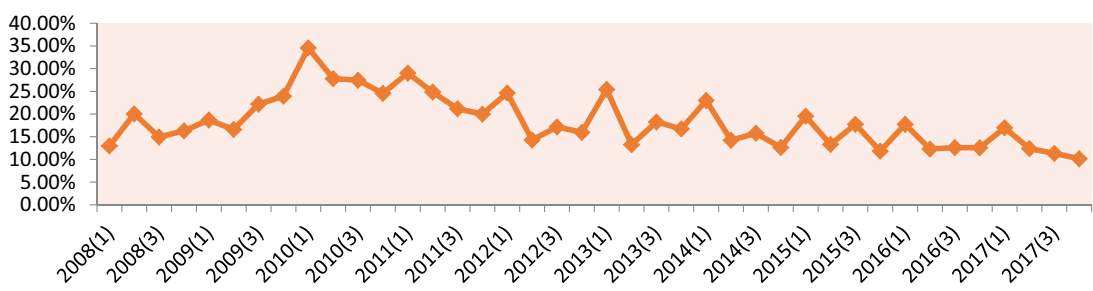

Fig. 1 The hidden economy during the years 2008-2017 quarterly. The figure shows the percent change in the Palestine hidden economy over the period 2008-2017 based on the data shown in Table 2.

\begin{tabular}{|ll|}
\hline Table 3 VECM estimation results. & \\
Error correction: & D(LHE) \\
\hline CointEq1 & 0.232378 \\
& $(0.34599)$ \\
& {$[0.67163]$} \\
$D(L H E(-1))$ & Prob. $=0.5070$ \\
\hline
\end{tabular}

Table 4 FMOLS estimation results.

\begin{tabular}{|lcccl} 
& \multicolumn{3}{l}{ Dependent variable: Ln (HE) } & \\
\cline { 2 - 5 } & Coefficient & Std. error & t-Statistic & Prob. \\
\hline$C$ & 7.479192 & 0.915577 & 8.168827 & 0.0000 \\
$\operatorname{Ln}(T / Y)$ & 0.812669 & 0.039583 & 20.53073 & 0.0000 \\
$\operatorname{Ln}(W / Y)$ & 0.038089 & 0.041654 & 0.914431 & 0.3671 \\
$\operatorname{Ln} R$ & -0.450088 & 0.018493 & -24.33880 & 0.0000 \\
$\operatorname{Ln}(S E)$ & 0.825721 & 0.189381 & 4.360118 & 0.0001 \\
$\operatorname{Ln}\left(G D P_{P C}\right)$ & 0.350225 & 0.131028 & 2.672907 & 0.0116 \\
\hline
\end{tabular}

commercial banks; $(\mathrm{SE})_{t}$ : the ratio of workers in their own private business to the ratio of actual workers; GDP-PC: Per capita GDP; and $\varepsilon_{t}$ : random error.

FMOLS was used to estimate the function of the model of regression of underground economy because the dependent variable is represented with the natural logarithm of the size of the underground economy in Palestine with the rest of independent variables. Table 4 shows the results of estimating the function of the model with FMOLS. Through the results of estimating the function of model of regression of underground economy with FMOLS, it was clarified that all the independent variables have statistical function at the level of $5 \%$ except the variable $(\operatorname{Ln}(W / Y))$, which is the whole ratio of wages and salaries to the ratio of GDP. The value of adjusted coefficient reached 0.974 showing that the independent variables in the model of the study are $\sim 97.4 \%$ of the actual change affecting the dependent variable (Palestinian underground economy) and $\sim 2.6 \%$ of the actual change affecting the dependent variable can be attributed to other factors that are not addressed or inserted in the model of the proposed underground economy.

Figure 2 shows the extent of the approximation of real and estimated values, which points to the fact that there is a very high rate of consistency and confirming quality. There is no need to check the problems of autocorrelation and the consistency of discrepancy for the series of residuals because the FMOLS was in estimating the model.

The impact of tax on the Palestine underground economy. Table 4 shows the results of the test of estimating the function of the model of regression of underground economy for the variable of the ratio of taxes with the use of FMOLS. The results reveal that the value of test of $t$-statistic (20.53) has a mathematical function (the level of function is $<0.05$ ) confirming the truth of the hypothesis and proving that there is a relationship having statically function. Thus, the previous hypothesis is accepted, and this can be clarified through the value of the flexibility of 0.813 and this shows that each increase with the rate of $10 \%$ in the value of tax as a rate of GDP will be offset by an increase of $10 \%$ of the size of the underground economy. It can be concluded that the taxes significantly impact the increase in the size of the underground economy, making one conclude that tax evasion is one of the critical factors affecting the size of the underground economy. This conclusion is assured by Tanzi, who found that the rate of tax positively impacts the sum of cash the people have. For this reason, Tanzi built his hypothesis to neutralize the underground economy by assuming that all the transactions of the underground economy are achieved with the use of currency cash for tax evasion. This result is aligned with the study of Giles (1999) that namely addresses tax liability and tax evasion that impact the increase in the size of the underground economy and tax gap in New Zealand. It is also aligned with another study of Mughal and Schneider (2018) whose most essential results show that increasing taxes causes an increase in the size of the underground economy. There is another similar study, Nchor and Konderla (2016), which affirms that the average rate of the underground economy in the Czech Republic is $20.9 \%$ at the end of the year 2013 and the state loses an average rate of tax income of $\sim 7.2 \%$ of the GDP each year because of tax evasion.

From the above, as for the government, it can be concluded that this variable should reconsider by changing the tax policy or increasing the commitment to pay the tax liability in all sectors or staying away from tax reconciliation.

The impact of government wages and salaries on the Palestine underground economy. Table 4 demonstrates the results of the test of estimating the function of the model of regression of underground economy for the variable of wages and salaries with the use of FMOLS. The variable of governmental wages and salaries was used for the first time to estimate the size of the underground economy due to the situation of Palestine that depends on the governmental salaries in moving the economy. It is noted from the results of the previous table that the value of the test $t$-statistic (0.914) has not statistical function (the level of function is more significant than 0.05 ) which denies the validity of the hypothesis showing that there is no relationship lacking statistical function. It shows that all salaries have a statistical function in the underground economy. This can lead one to conclude that government salaries are not sufficient or they are hardly sufficient to fulfil the needs of government workers. This also can indicate that part of government workers works for their private business indicating that tax evasion has other impacts including lack of professional commitment in the government job or non-fulfilment of job duties on account of running a private business. 


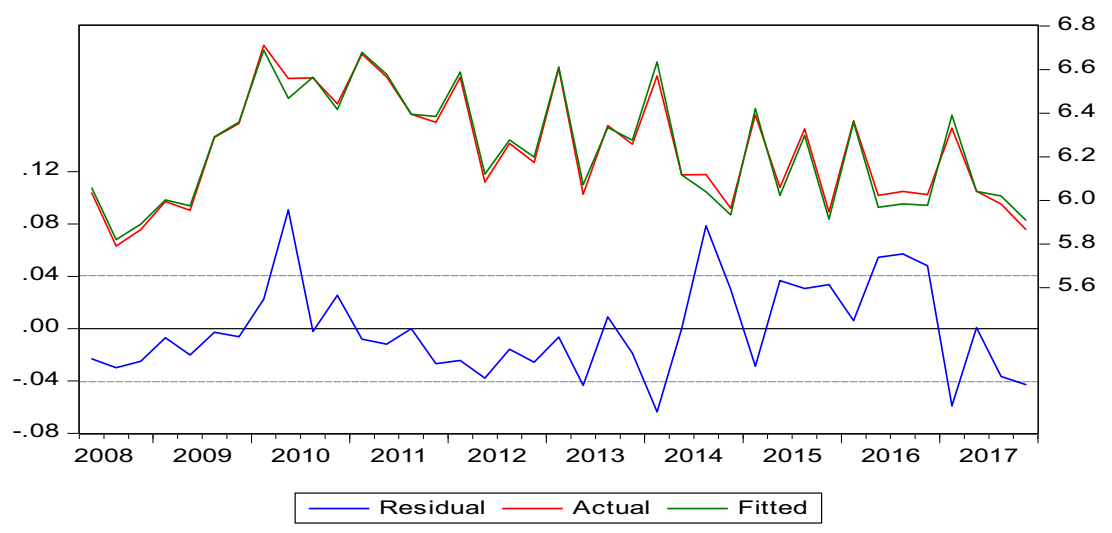

Fig. 2 The real and estimated values of residuals for the model of underground economy fully modified ordinary least squares (FMOLS). This figure depicts the extent of the approximation of real and estimated values, which points to the fact that there is a very high rate of consistency and confirming quality, meaning that the model is not violated by problems of autocorrelation and persistence of discrepancy for the series of residuals due to using the FMOLS.

The impact pf interest rate of deposits in commercial banks on the Palestine underground economy. Table 4 demonstrates the results of the test of estimating the function of the model of regression of the underground economy for the variable of interest rate with the use of FMOLS.

It is noted from the results of the previous table that the value of the test $t$-statistic $(-24.34)$ has a statistical function (the level of function is $<0.05$ ) which confirms the validity of the hypothesis showing that there is relationship having a statistical function. Thus, the previous hypothesis will be accepted. This was clarified through the value of the flexibility of the variable $(-0.45)$, and this indicates that each increase with the rate of $10 \%$ in the interest rate is offset by a decrease with rate of $4.5 \%$ in the size of the underground economy. This result is aligned with all previous studies indicating that the more size of the underground economy there is, and more belief there is in the investment in bank deposits, less currency cash there will be causing a decrease in the size of the Underground Ground (Filho, 2012; Ardizzi et al., 2014; Nchor and Konderla, 2016; Raut et al., 2016; Watson, 2004). This can make one conclude that encouraging investment through deposits is essentially needed, which needs developing the work of banks and increasing the size of investment through a practical plan ad Palestinian by the government and implemented by the monetary authority.

The impact of workers working in their private Business for a real number of workers on the Palestine underground economy. Table 4 demonstrates the results of the test of estimating the function of the model of regression of the underground economy for the variable of workers working in their private Business for a real number of workers with the use of FMOLS. It is noted from the results of the previous table that the value of the test $t$-statistic $(-24.36)$ has a statistical function (the level of function is $<0.05$ ), which confirms the validity of hypothesis showing that there is relationship having a statistical function. Thus, the previous hypothesis will be accepted. This was clarified through the value of the flexibility of the variable $(-0.826)$, and this indicates that each increase with the rate of $10 \%$ in several workers working for their private business is offset an increase with the rate of $26 \%$ in the size of the underground economy. This result is aligned with all previous studies indicating that the more size of the underground economy. This supports the concluded belief that the workers working in their private business seek tax evasion and working in the formal economy, supporting the relationship between salaries and workers who work in their private business. The governmental salaries have not impacted the underground economy, pushing workers to work in their private business. This caused tax evasion and work of workers in their private business (Filho, 2012).

The impact of per-capita GDP on the Palestine underground economy. Table 4 demonstrates the results of the test of estimating the function of the model of regression of the underground economy for the variable of per capita GDP with the use of FMOLS.

It is noted from the results of the previous table that the value of the test $t$-statistic (2.67) has a statistical function (the level of function is $<0.05$ ), which confirms the validity of the hypothesis showing that there is a relationship having a statistical function. Thus, the previous hypothesis will be accepted. This was clarified through the value of the flexibility of the variable (0.35), and this indicates that each increase with the rate of $10 \%$ in the value of per capita GDPs offset an increase with the rate of 3.5\% in the size of the underground economy. This indication had not lived up to expectations, and this result leads one to conclude that Palestinian citizen still believes in dealing with cash currency, although there is an increase in his per capita GDP. Therefore, the increase in income means that there will be more and more increase in currency cash in the hands of citizens, causing an increase of currency cash outside the bank system. We assumed since the beginning that all transactions of the underground economy are treated far from cash currency outside the bank system (Schneider, 2008; Raut et al., 2016).

\section{Concluding remarks}

As aforesaid, the econometric results showed that all the variables have statistical function except the variable of the government salaries and wages which indicates that the value of salaries the workers in governmental gain do not contribute in the underground economy because of the low wages of workers of governmental sector and high cost of living. However, we conclude that such conditions push them to work sometimes outside the formal economy, increasing the size of the underground economy. Their numbers could not be estimated under the part of workers. It was expected that per-capita GDP had not lived up to the expectation since it was expected to have negative sign while it was positive which means that the Palestinian citizen continues to deal with currency cash while he does not use the modern financial tools as (cheques-credit cards). The rest of the expected signs cam aligned with the results. The result of estimating the model of correcting errors (VECM) was that there is no balance 
between independent variables and dependent variables of underground economy on the long term and balance could be reached on the long term.

The size of the underground economy in Palestine was approximately estimated $275.036-821.819$ US million during 2008-2017, and the average value was estimated at 518.7232 US million, and the rate was $28.60-12.71 \%$ and its average rate was $18.37 \%$. The year of 2017 as a one of the study years has witnessed the lowest level of the underground economy as the average size on the level of quarters was 433.1569 USD million with the rate of $12.71 \%$. The lowest quarter was recorded in the first quarter of the year of 2008 with the sum of 275.036 UDS million with the rate of $12.97 \%$ and the highest level of the underground economy had been recorded during the year of 2010 as a year of the study years with the average sum at level of quarters of 715.89 USD million with the rate of $28.60 \%$ first quarter of 2010 had witnessed the highest level with sum of 821.8185 USD million with the rate of $34.57 \%$. All signs of the transactions of independent variables of the study were positive indicating that they are directly connected to the size of the underground economy except the variable of the interest rate of bank deposits in US dollar in commercial banks. $R$ has a negative sign. The Palestinian underground economy is positively affected by some of the variables. It is found that the flexibility of the rate of tax (without tax clearance) to the ratio of nominal GDP (T/Y) as a rate of GDP is offset an increase with the rate of $8.13 \%$ in the size of the underground economy. It was also noted that the flexibility of the ratio of the workers running their own private business to the ratio of actual workers (SE) was (0.826) meaning that if it is assumed that all other variables and factors are stationary, an increase of $10 \%$ in the number of workers in their private business in relation to the actual number of workers will be offset with an increase of $8.26 \%$ in the size of the underground economy. It was found that the flexibility of per capita GDP (GDP-PC) reached (0.35). Assuming that the other factors and variables are stationary, if the average income of the Palestinian citizen is increased with the rate of $10 \%$ every year, that increase will increase the size of the underground economy with the rate of $3.5 \%$. The variable of the interest rate of the saving deposits in US dollar in commercial banks $(R)$ has positive impact indicating that it hurts the size of the underground economy with the flexibility correlation of -0.450 . This means that if commercial banks increase the interest rates to the deposits of citizens with a rate of $10 \%$, the size of the underground economy will be decreased with $4.5 \%$ with the stationary of other variables.

\section{Policy recommendations}

The empirical results of the study and the above concluding remarks allowed the researchers to provide several policy recommendations to both policymakers and researchers. They comprise: (1) the Palestinian government should pay more attention to the sector of the underground economy by conducting studies showing its economic benefit and future horizons to provide some necessary data about this sector and to be easily monitored; (2) the Palestinian policymakers should prepare a new strategy that could reduce the phenomena of the underground economy through by designing policies and drafting suitable legislation that fit the Palestinian context. The underground economy should be integrated with the formal economy instead of reducing it according to a clear plan seeking to achieve that integration. The government should conduct raising awareness campaigns to raise the awareness of the community about the necessity of adherence to laws and regulations for the public interest. The government should also reconsider the tax policy as it negatively impacts the social and economic conditions. It also should promote the status of the underground economy. It must seek to build a strong economy that could face all the crises that take place from time to time, whether they are political crises, closures, or wars to reduce the underground economy; (3) local banks should be encouraged for investment to create an investment environment that could increase the saving deposits (Awad et al., 2019); (4) the ministry of the national economy should register all the operations of smuggling goods, including all the kinds of goods and their financial costs by receiving information from Customs Brigade or other security departments; (5) the database of the judicial system should be developed to include all the components of the underground economy to control all cases and crimes happening inside the underground economy; (6) the system of Palestinian statistics should be developed to include estimating the size of the underground economy or informal economy as developing this system will give numbers and statistics needed for building strategies of economic development, and (7) the monetary authority should continue publishing quarterly data and auditing that data since it has been lost during past years and their values had been changed.

\section{Data availability}

The data and materials used in this paper were collected from the Palestine Monetary Authority (PMA) and the Palestinian Central Bureau of Statistics (PCBS).

Received: 2 December 2019; Accepted: 5 March 2020; Published online: 31 March 2020

\section{References}

Ardizzi G, Petraglia C, Piacenza M, Turati G (2014) Measuring the underground economy with the currency demand approach: a reinterpretation of the methodology, with an application to Italy. Rev Income Wealth 60(4):747-772

Asiedu E, Stengos T (2014) An empirical estimation of the underground economy in Ghana. Economics Research International, Article ID 891237

Awad IM, Al Karaki MS (2019) The impact of bank lending on Palestine economic growth: an econometric analysis of time series data. Financ Innov. 5:14

Becker S (1968) Crime and punishment: an economic approach. J Political Econ 76:169-217

Cagan P (1958) The demand for currency relative to the total money supply. J Polit Econ 66(3):302-328

Carolina M, Pau L (2007) The shadow economy in the Netherlands Antilles, Bank van de Nederlands Antillen-Working Papers BNA/WP07/01

Del'Anno R, Schneider F (2004) The shadow economy of Italy and other OECD countries: what do we know? Discussion Paper. Department of Economics, University of Linz, Linz, Austria

Dell'Anno R (2003) Estimating the shadow economy in Italy: a structural equation approach, Working Paper 2003-7. Department of Economics, University of Aarhus, Aarhus, Denmark

Dybka P, Kowalczuk M, Olesinski B, Toroj A, Rozkrut T (2019) Currency demand and MIMIC models: towards a structured hybrid method of measuring the shadow economy. Int Tax Public Financ 26(1):4-40

Engle R, Granger J (1987) Co-integration and error correction: representation, estimation and testing. Econometrica 55(2):251-276

Feige EL (1986) A re-examination of the underground economy in the United States, IMF Staff Papers, 33, pp 768-781

Feige EL (ed.) (1989) The underground economies. Tax evasion and information distortion. Cambridge University Press, Cambridge, pp 361-378

Feige EL (1994) The underground economy and the currency enigma. Suppl Public Financ/Financ Publiques 49:119-136

Filho F (2012) An estimation of the underground economy in Brazil. IBRE-FGV/ ETCO Institute

Frey BS, Pommerehne W (1984) The hidden economy: state and prospect for measurement. Rev Income Wealth 30(1):1-23

Giles A (1999) Measuring the hidden economy: implications for econometric modelling. Econ J 109(456):370-380

Gutmann PM (1977) Subterranean economy. Financ Anal J 34(6):26-27

Hanninen R (2012) The law of one price in United Kingdom soft sawnwood imports-a cointegration approach. Modern time series analysis in forest products markets. Springer, p 66 
Kwiatkowski D, Phillips PCB, Schmidt P, Shin Y (1992) Testing the null hypothesis of stationarity against the alternative of a unit root: how sure are we that economic time series have a unit root? J Econ 54(1-3):159-178

Lippert O, Walker M (eds.) (1997) The underground economy: global evidences of its size and impact. The Frazer Institute, Vancouver

MacKinnon JG (1996) Numerical distribution functions for unit root and cointegration tests. J Appl Econom 11:601-618

McClelland J, Schulze. W (1992) Why do people pay taxes? J Public Econ 48 (1):21-38

Medina L, Schneider F (2018) Shadow economies around the world: what did we learn over the last 20 years? WP/18/17, IMF Working papers

Montgomery C, Peck A, Vining G (2012) Introduction to linear regression analysis, 4 th edn. Wiley, New York

Mughal K, Schneider F (2018) Shadow economy in Pakistan: its size and interaction with official economy. MPRA paper 87087. University Library of Munich, Germany

Nchor D, Konderla T (2016) The shadow economy of Czech Republic and tax evasion: the currency demand approach. Acta Univ Agric Silvic Mendel Brun 64(6):2081-2086

Ogunc F, Yilmaz G (2000) Estimating the underground economy in Turkey. The Central Bank of the Republic of Turkey Research Department Discussion Paper

Park Y (1992) Canonical cointegrating regressions. Econom Econom Soc 60 (1):119-143

Raut N, Chalise N, Thapa P (2016) Measurement of the underground economy in Nepal: a currency demand approach. Econ J Dev Issues 17(1-2):105-127

Razali N, Wah B (2011) Power comparisons of Shapiro-Wilk, Kolmogorov-Smirnov, Lilliefors and Anderson-Darling tests. J Stat Model Anal 2(1):21-33

Said S, DIickey D (1984) Testing for unit roots in autoregressive-moving average models of unknown order. Biom J 71(3):599-607

Schneider F (1994a) Measuring the size and development of the shadow economy. Can the causes be found and the obstacles be overcome? In: Brandstaetter $\mathrm{H}$, Güth W (eds.) Essays on economic psychology. Springer Publishing Company, Berlin, Heidelberg, pp 193-212

Schneider F (2005) Shadow economies around the world: what do we really know? Eur J Political Econ 21(3):598-642

Schneider F (ed.) (2008) The economics of the hidden economy. Edward Elgar, Cheltenham II, pp 79-96

Schneider F (ed.) (2011) Handbook on the shadow economy. Edward Elgar, Cheltenham

Schneider F, Buehn A (2018) Estimating the size of the shadow economy: methods, problems and open questions. De Gruyter Open Econ 1(1):1-199

Smith P (1994) Assessing the size of the underground economy: the Canadian statistical perspectives. Can Econ Obs 11:16-33

Tanzi V (1980) The underground economy in the United States: estimates and implications. PSL Q Rev 135:427-453

Tanzi V (1983) The underground economy in the United States: annual estimates, 1930-1980. IMF Staff Pap 30:283-305
Tanzi V (1999) Uses and abuses of estimates of the underground economy. Econ J 109(3):338-347

Tyler TR, Boeckmann RJ, Smith HJ, Huo YJ (1997) Social Justice in a Diverse Society. Westview Press, Boulder, Colo, USA

Watson K (2004) Measuring the size of the hidden economy in Trinidad \& Tobago, 1973-1999. Int Econ J 20(3):321-341

\section{Acknowledgements}

In preparation for this paper, I had to take the help of some respected professors in empirical economics, who deserve my deepest gratitude. As the completion of this paper gave me much pleasure, we would like to express my appreciation for all those who have directly and indirectly helped us in preparing this research paper.

\section{Author contributions}

The co-authors made a significant contribution and agreed with the contents of this paper.

\section{Competing interests}

The authors declare no competing interests.

\section{Additional information}

Correspondence and requests for materials should be addressed to I.M.A.

Reprints and permission information is available at http://www.nature.com/reprints

Publisher's note Springer Nature remains neutral with regard to jurisdictional claims in published maps and institutional affiliations.

(c) (i)

Open Access This article is licensed under a Creative Commons Attribution 4.0 International License, which permits use, sharing, adaptation, distribution and reproduction in any medium or format, as long as you give appropriate credit to the original author(s) and the source, provide a link to the Creative Commons license, and indicate if changes were made. The images or other third party material in this article are included in the article's Creative Commons license, unless indicated otherwise in a credit line to the material. If material is not included in the article's Creative Commons license and your intended use is not permitted by statutory regulation or exceeds the permitted use, you will need to obtain permission directly from the copyright holder. To view a copy of this license, visit http://creativecommons.org/ licenses/by/4.0/.

(C) The Author(s) 2020 


\section{QUERY FORM}

\section{PALCOMMS}

Manuscript ID

Author

Editor

Publisher
[Art. Id: 433]

\section{Journal: PALCOMMS}

Author :- The following queries have arisen during the editing of your manuscript. Please answer by making the requisite corrections directly in the e.proofing tool rather than marking them up on the PDF. This will ensure that your corrections are incorporated accurately and that your paper is published as quickly as possible.

\begin{tabular}{|c|l|l|}
\hline $\begin{array}{c}\text { Query } \\
\text { No. }\end{array}$ & Description & Author's Response \\
\hline & No queries & \\
\hline
\end{tabular}

